\title{
Produção e valor nutritivo de capim-piatã submetido à adubação orgânica e química
}

\author{
Thiago Trento BISERRA ${ }^{*}$, Luísa Melville PAIVA, Henrique Jorge FERNANDES1, \\ Camila Fernandes Domingues DUARTE ${ }^{1}$, Alex Coene FLEITAS ${ }^{1}$, Ademir Oliveira da SILVA ${ }^{1}$
}

${ }^{1}$ Universidade Estadual de Mato Grosso do Sul, Aquidauana, Mato Grosso do Sul, Brasil. (ORCID: *; 0000-0003-4726-943X; 0000-0001-7617-9711; 0000-0002-9776-1353; 0000-0002-2637-0080; 0000-0003-3248-7792) *E-mail: thiagotrento26@gmail.com (ORCID: 000-0002-6130-9787)

Recebido em 25/10/2018; Aceito em 21/11/2019; Publicado em 04/02/2020.

\begin{abstract}
RESUMO: A adubação orgânica pode ser utilizada de forma sustentável visando o fornecimento de nutrientes as plantas. No entanto, são restritas as informações referentes às doses a serem aplicadas. Objetivou-se avaliar o desenvolvimento e valor nutritivo de capim-piatã recebendo diferentes níveis de biofertilizante $(0,1,0,2,0$, 3,0 e 4,0 L de biofertilizante líquido de esterco bovino por vaso) e diferentes condições de adubação química (dose zero - controle, com aplicação de 50 e 100\% da recomendação de adubação química). O biofertilizante associado ou não com adubação química proporcionou aumentos na massa de forragem, massa de raiz e altura final das plantas e redução da razão parte aérea:raiz. A concentração proteína bruta foi influenciada pelos níveis de biofertilizante aplicado, na ausência de adubação química. As concentrações de fibra em detergente neutro e fibra em detergente ácido responderam de forma quadrática aos níveis de biofertilizante utilizado, quando foram associadas a $100 \%$ da dose recomendada de adubação química. Quando 50\% da recomendação adubação química foi utilizada a fibra em detergente ácido aumentou linearmente. A utilização de biofertilizante pode ser uma alternativa promissora em substituição total ou parcial da adubação química, melhorando o desenvolvimento e valor nutritivo do capim- piatã na implantação.
\end{abstract}

Palavras-chave: biofertilização; Brachiaria briæantha cv. BRS Piatã; desenvolvimento sustentável.

\section{Production and nutritive value of piatã palisade grass submitted to organic and chemical fertilization}

\begin{abstract}
Organic fertilization can be used sustainably in providing nutrients to plants. However, information regarding the doses to be applied is restricted. The objective was to evaluate the development and nutritional value of piatã palisade grass receiving different levels of biofertilizer $(0,1.0,2.0,3.0$ and $4.0 \mathrm{~L}$ of liquid bovine manure biofertilizer) and different conditions of chemical fertilization (zero dose - control, applying 50 and $100 \%$ of the chemical fertilization recommendation). The biofertilizer associated or not with chemical fertilization provided increases in forage mass, root mass and final plant height and reduced shoot: root ratio. The crude protein concentration was influenced by the levels of biofertilizer applied in the absence of chemical fertilization. The concentrations of neutral detergent fiber and acid detergent fiber concentrations responded quadratically to the levels of biofertilizer used, when they were associated with 100\% of the recommended chemical fertilizer dose. When $50 \%$ of the chemical fertilizer recommendation was used the acid detergent fiber increased linearly. The use of biofertilizer can be a promising alternative in total or partial substitution of chemical fertilization, improving the development and nutritional value of the piatã palisade grass at implantation.
\end{abstract}

Keywords: biofertilization; Brachiaria brizantha cv. BRS Piatã; sustainable development.

\section{INTRODUÇÃO}

A produção de ruminantes a pasto é resultante da massa de forragem disponível e seu valor nutritivo, que por sua vez, depende dos fatores bióticos e abióticos em diferentes intensidades. Entre os fatores, o correto fornecimento de nutrientes é essencial para a máxima produtividade forrageira e melhorias na sua qualidade. Manter o requerimento de nutrientes nas pastagens de clima tropical em níveis adequados, também garante a perenidade do sistema produtivo (PRIMAVESI et al., 2006). Dentre as alternativas para nutrição das plantas, o uso de biofertilizantes tem se mostrado uma opção promissora e de baixo custo para fornecimento de nutrientes no estabelecimento e recuperação de pastagens (SOARES FILHO et al., 2015).

O biofertilizante é um subproduto obtido da fermentação de resíduos agrícolas ou dejetos de animais que podem substituir ou complementar a adubação química (SOUSA et al., 2013). Estes podem ser utilizados nos solos ou em tratamentos foliares (LIMA et al., 2012). Os biofertilizantes possuem em sua composição macro e micronutrientes orgânicos e inorgânicos, na maioria, essenciais ao desenvolvimento e crescimento das plantas, mas em menores concentrações em relação aos fertilizantes químicos 
(ARAÚJO et al., 2011). Além de contribuir para as características químicas do solo, os biofertilizantes também melhoram as características físicas, como aumento na capacidade de retenção de água, agregação do solo e porosidade (LEAL; SILVA, 2002).

Em plantas forrageiras, a aplicação de biofertilizantes como estratégia de fornecimento de nutrientes tem garantido aumento no acúmulo de forragem. No capim Tifton 85, Erthal et al. (2010) verificaram que a aplicação de água residuária de bovinocultura resultou em maior acúmulo de forragem com maiores concentrações de proteína bruta. Resultados semelhantes foram observados no capim-piatã adubado com diferentes doses de biofertilizante, com aumento linear no acúmulo forragem, além de melhorias no valor nutritivo (ORRICO JUNIOR et al., 2012; ORRICO JUNIOR et al., 2013).

Apesar dos resultados positivos na parte aérea das plantas forrageiras com a utilização de biofertilizantes, ainda são escassos os resultados sobre o efeito no sistema radicular dessas plantas. Assim, objetivou-se com esse trabalho avaliar as características produtivas e valor nutritivo do capim-piatã (Brachiaria brizantha cv. BRS Piatã) recebendo diferentes níveis de adubação orgânica (biofertilização) em diferentes condições de adubação química, em ambiente protegido de cultivo.

\section{MATERIAL E MÉTODOS}

O experimento foi realizado em estufa agrícola da Fazenda UEMS/Unidade Universitária de Aquidauana ( $20^{\circ} 28^{\prime}$ de latitude sul e $55^{\circ} 48^{\prime}$ longitude oeste, e $149 \mathrm{~m}$ de altitude), de agosto a dezembro de 2013. O clima da região é Tropical Savana (Aw), segundo classificação de Köppen, dividido em duas estações: chuvosa e seca.

Os tratamentos consistiram de quatro doses de biofertilizante líquido de esterco bovino (1,0; 2,0; 3,0 e 4,0 L vaso $^{-1}$ ) e um controle (sem biofertilizante líquido de esterco bovino), avaliados sob três condições de adubação química (dose zero - controle, com aplicação de $50 \%$ da recomendação de adubação química e com aplicação de $100 \%$ da recomendação de adubação química). Para cada dose de biofertilizante, em cada condição de adubação química, utilizou-se quatro repetições.

O biofertilizante foi preparado a partir de uma mistura contendo esterco bovino fresco e água na proporção de 50\% (volume $/$ volume $=\mathrm{v} / \mathrm{v})($ PENTEADO, 2007). Para se obter um sistema anaeróbio de fermentação, a mistura foi colocada em uma bombona plástica com capacidade para $200 \mathrm{~L}$ (PENTEADO, 2007). Após 30 dias de fermentação da mistura, o material foi peneirado em peneiras de 4,0 $\mathrm{mm}$ de malha, e separada a parte líquida da sólida, sendo a parte líquida considerada o biofertilizante. $\mathrm{O}$ biofertilizante produzido apresentou as seguintes características: $\mathrm{N}=0,496$ $\mathrm{g} \mathrm{L}^{-1} ; \mathrm{P}=0,128 \mathrm{~g} \mathrm{~L}^{-1} ; \mathrm{K}=0,095 \mathrm{~g} \mathrm{~L}^{-1} ; \mathrm{Ca}=0,410 \mathrm{~g} \mathrm{~L}^{-1} ; \mathrm{Mg}=$ $1,952 \mathrm{~g} \mathrm{~L}^{-1} ; \mathrm{Al}=0,009 \mathrm{~g} \mathrm{~L}^{-1} ; \mathrm{Fe}=0,040 \mathrm{~g} \mathrm{~L}^{-1} ; \mathrm{Mn}=0,024 \mathrm{~g} \mathrm{~L}^{-}$ 1; $\mathrm{Cu}=0,002 \mathrm{~g} \mathrm{~L}^{-1} ; \mathrm{Zn}=0,012 \mathrm{~g} \mathrm{~L}^{-1}$.

O solo utilizado nos vasos foi coletado e classificado como Latossolo vermelho distrófico (SANTOS et al., 2013), o qual foi peneirado em peneiras de 4,0 $\mathrm{mm}$ de malha, para homogeneização. A análise química demostrou as seguintes características: $\mathrm{pH} \mathrm{H} \mathrm{H}_{2} \mathrm{O}=5,40 ; \mathrm{P}=2,90 \mathrm{mg} \mathrm{dm}^{-3} ; \mathrm{M} . \mathrm{O}=9,00$ $\mathrm{g} \mathrm{dm}^{-3} ; \mathrm{K}=0,40$ mmolc $\mathrm{dm}^{-3} ; \mathrm{Ca}=6,00$ mmolc dm$^{-3} ; \mathrm{Mg}=$
5,00 mmolc $\mathrm{dm}^{-3} ; \mathrm{Al}=8,00$ mmolc $\mathrm{dm}^{-3} ; \mathrm{H}+\mathrm{Al}=30,00$ mmolc dm ${ }^{-3} ; \mathrm{S}=14,00$ mmolc $\mathrm{dm}^{-3} ; \mathrm{T}=41,14$ mmolc dm $^{-3}$.

Com base na análise química, as quantidades de N-P-K recomendadas foram: 150 , 40 e $50 \mathrm{~kg} \mathrm{ha}^{-1}$, respectivamente, de acordo com as recomendações de Martha Júnior et al. (2007) para capim-piatã, no estabelecimento. Para 100\% da recomendação foram aplicados: $2,52 \mathrm{~g} \mathrm{vaso}^{-1} \mathrm{de} \mathrm{N}, 1,67 \mathrm{~g}$ vaso $^{-1}$ de $\mathrm{Pe} \mathrm{e} 0,64 \mathrm{~g}$ vaso $^{-1}$ de $\mathrm{Ke}$, para $50 \%$ da recomendação: $1,26 \mathrm{~g}$ vaso $^{-1}$ de $\mathrm{N}, 0,84 \mathrm{~g}$ vaso $^{-1}$ de $\mathrm{P}$ e $0,32 \mathrm{~g}$ vaso $^{-1}$ de $\mathrm{K}$ respectivamente. A fonte de nitrogênio $(\mathrm{N})$ utilizada foi $\mathrm{O}$ Nitro Mais ${ }^{\circledR}(45 \%$ de N) (Fertilizantes Heringer, Viana, ES), a fonte de fósforo (P) foi superfosfato simples $(16 \%$ de P2O5) e de potássio $(\mathrm{K})$, o cloreto de potássio (42\% de $\mathrm{K} 2 \mathrm{O})$.

Foram utilizados vasos com capacidade de $15 \mathrm{dm}^{3}$, preenchidos com solo e deixados para estabilização por 28 dias. Nesse período, a umidade do solo nos vasos foi monitorada diariamente através de pesagem, sendo corrigida sempre que necessário, para que o solo permanecesse a $80 \%$ da capacidade de retenção de água. Simultaneamente, o capim-piatã foi semeado em bandejas plásticas de 200 células, com substrato comercial e mantido por 28 dias. Após o período de estabilização foram transplantadas 10 plântulas por vaso. Após 14 dias de cultivo foi realizado o desbaste, salvaguardando-se as quatro plantas mais vigorosas e semelhantes por vaso. Os vasos foram irrigados diariamente, duas vezes ao dia sempre as 7:00 e 17:00 horas, com $500 \mathrm{ml}$ vaso $^{-1}$ de água.

Os adubos foram incorporados no solo com auxílio de um ferro, perfazendo três furos em cada vaso, de aproximadamente $10 \mathrm{~cm}$ de profundidade, objetivando melhorar a absorção dos nutrientes pelas plantas. As doses de nitrogênio $(\mathrm{N})$, fósforo $(\mathrm{P})$ e potássio $(\mathrm{K})$, foram divididas em três aplicações iguais, realizadas aos 7, 35 e 63 dias após o transplantio. As adubações por biofertilização com 200, 400,600 e $800 \mathrm{ml} \mathrm{vaso}^{-1}$, via foliar, foram realizadas no $15^{\circ}$ dia e quinzenalmente até 74 dias após transplantio.

Vinte e um dias após o transplantio realizou-se corte de uniformização das plantas a $15 \mathrm{~cm}$ de altura da superfície do solo. Após 90 dias de cultivo, foi realizada a medição da altura média em cada vaso, com régua graduada. $\mathrm{O}$ valor medido correspondeu à altura média da curvatura das folhas superiores em torno da régua (CECATO et al., 2001). Logo após, realizou-se o corte das plantas rente ao solo, com a utilização de uma tesoura. O material foi identificado, pesado e seco em estufa com ventilação forçada a $65^{\circ} \mathrm{C}$ por 72 horas (SILVA e QUEIROZ, 2002) para a determinação da massa seca. Depois de secas as amostras foram moídas em moinho tipo Willey (peneira de $1 \mathrm{~mm}$ ) e realizadas as análises bromatológicas.

Foram determinadas as concentrações de proteína bruta (PB) que foi determinada, multiplicando-se o teor de $\mathrm{N}$ por 6,25 , as frações de fibra em detergente neutro (FDN) e fibra em detergente ácido (FDA), seguindo o método de Silva; Queiroz (2002).

As raízes foram coletadas ao término do experimento, esvaziando-se os vasos e retiradas às raízes de cada vaso, delicadamente, primeiramente com auxílio de peneiras de malha de dois milímetros e posteriormente lavadas em água corrente até retirar todo o solo existente. Essas raízes foram colocadas para perder a umidade excessiva em bancada forrada com papel absorvente, identificadas, ensacadas e, em seguida, colocou-se o material para secar conforme descrito 
anteriormente. Para calcular a razão parte aérea:raiz, dividiuse a massa seca de forragem pela massa seca de raiz.

As interações entre adubação química e com o biofertilizante foram avaliadas. Os dados foram então analisados para o efeito do biofertilizante segundo um delineamento inteiramente casualizado, dentro de cada condição de adubação química. A soma de quadrados de tratamentos foi particionada em contrastes ortogonais para se avaliar os efeitos de uso de biofertilizante e os efeitos lineares e quadráticos do nível de biofertilizante. Utilizou-se o pacote estatístico SAS, versão 9.3 (SAS Institute Inc. Cary, CA), em um nível de significância de 5\%.

\section{RESULTADOS}

A massa de forragem e de raiz do capim-piatã foram influenciadas pelo uso do nível de biofertilizante aplicado, em todas as condições de adubação química. Quanto ao efeito dos níveis de biofertilizante aplicados, verificaram-se ajustes lineares positivos para a massa de forragem e massa de raiz em todas as condições de adubação química (Figura 1).
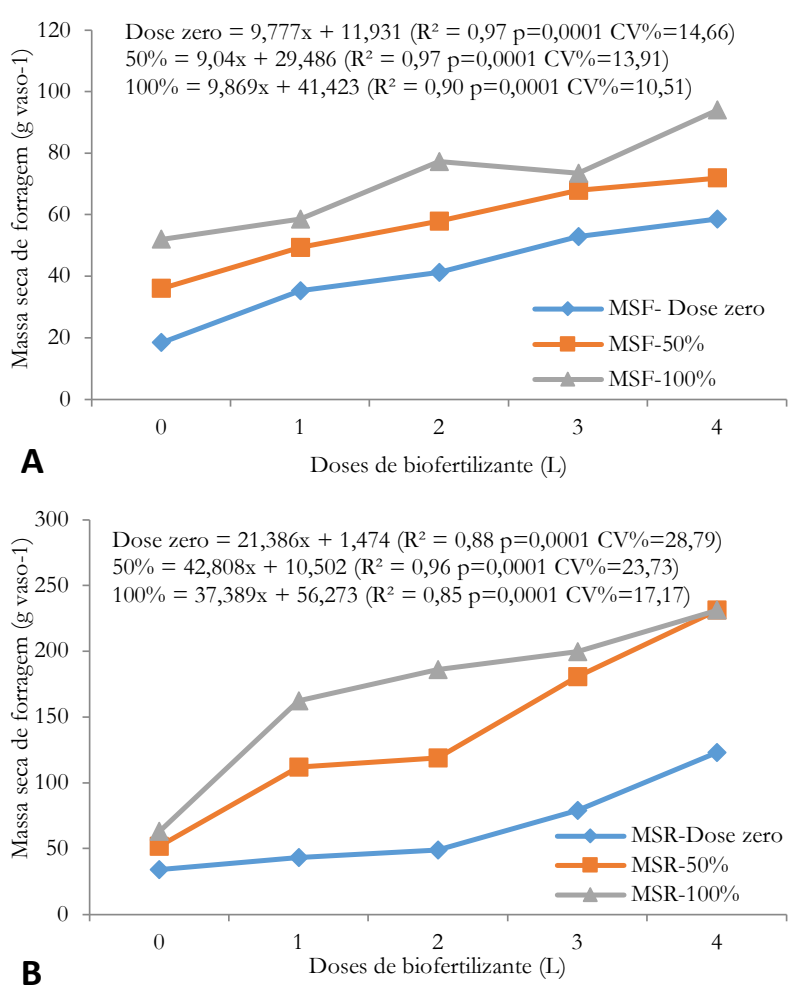

Figura 1. Massa seca de forragem (A) e massa seca de raiz (B) do capim-piatã recebendo biofertilizante com doses de adubo químico, cultivado em ambiente protegido.

Figure 1. Forage dry mass (A) and root dry mass (B) of piatã palisade grass receiving biofertilizer with doses of chemical fertilizer, cultivated in protected environment.

Na dose máxima de biofertilizante aplicado (4 L), a massa de forragem foi de $217 \%$ que o controle, na dose zero, $100 \%$ na aplicação de $50 \%$ da recomendação de adubação química e $81 \%$ superior quando $100 \%$ da recomendação de adubação química foi utilizada. $\mathrm{O}$ aumento na massa de raiz obtida com a aplicação de $4 \mathrm{~L}$ de biofertilizante, foi de $262 \%$ maior em comparação ao controle, na dose zero, $346 \%$ na utilização de $50 \%$ da recomendação de adubação química e $267 \%$ quando
$100 \%$ da recomendação de adubação química foi utilizada (Figura 1).

$\mathrm{Na}$ altura final e razão parte aérea:raiz do capim-piatã, observa-se que foram influenciadas pelo uso do nível de biofertilizante aplicado, em todas as condições de adubação química, exceto a altura final das plantas, quando 100\% da dose de adubação química foi utilizada. A altura da planta variou com o nível de biofertilizante aplicado, ajustando-se ao modelo linear positivo na ausência de adubação química (dose zero $=6,28 \mathrm{x}+79,42, \mathrm{R}^{2}=0,81$ ). Com isso, quando se utilizou $4 \mathrm{~L}$ de biofertilizante, observou-se aumento de $36 \%$ em relação ao controle na dose zero.

O nível de biofertilizante influenciou a razão parte aérea:raiz e a equação de regressão ajustou-se ao modelo quadrático na ausência de adubo químico (dose zero= $\left.0,0771 \mathrm{x}^{2}+0,4369 \mathrm{x}+0,226, \mathrm{R}^{2}=0,92\right)$. A máxima relação parte aérea:raiz foi observado quando se aplicou 2,83 L, com relação de 0,84 , sendo que, a partir dessa dose de biofertilizante, houve redução. Observou-se ainda efeito $(\mathrm{P}<0,05)$ linear negativo do nível de biofertilizante aplicado sobre a razão parte aérea:raiz com $50 \%$ da dose recomendada de adubação química $\left(50 \%=-0,088 \mathrm{x}+0,74, \mathrm{R}^{2}=0,80\right)$ e linear negativa quando $100 \%$ da dose recomendada de adubação química foi utilizada $\left(100 \%=-0,089 \mathrm{x}+0,76, \mathrm{R}^{2}=\right.$ $0,48)$ (Tabela 1).

O uso e nível de biofertilizante utilizado influenciaram $(\mathrm{P}<0,05)$ as proporções dos nutrientes contidos na MS das plantas (Tabela 2). A concentração de fibra em detergente neutro (FDN) e fibra em detergente ácido (FDA) variaram com o uso do nível de biofertilizante aplicado, quando 100\% da recomendação de adubação química ou quando $50 \%$ da recomendação de adubação química foram utilizadas, para FDN e FDA, respectivamente.

A proteína bruta $(\mathrm{PB})$ apresentou efeito linear positivo do nível de biofertilizante aplicado na análise de regressão $(\mathrm{P}<0,05)$ na ausência de adubação química (dose zero $\left.=2,956 \mathrm{x}+56,324, \mathrm{R}^{2}=0,96\right)$. Os valores variaram de $60,20 \mathrm{~g} \mathrm{~kg}^{-1}$ na ausência de adubação química para $71,58 \mathrm{~g} \mathrm{~kg}^{-}$ ${ }^{1}$, quando $4 \mathrm{~L}$ de biofertilizante foi utilizado, proporcionando aumento de $19 \%$ nessa variável, quando comparado à ausência de adubação química (Tabela 2).

Ao analisar a concentração de FDN em função do nível de biofertilizante aplicado, constatou-se comportamento quadrático positivo quando $100 \%$ da dose recomendada de adubação química foi aplicado $\left(100 \%=-14,63 x^{2}+94,828 x+\right.$ $\left.519,81, \mathrm{R}^{2}=0,99\right)$. Dessa forma, a máxima concentração de FDN foi encontrada quando se aplicou 3,24 L, com 673,47 g $\mathrm{kg}^{-1}$, sendo que, a partir dessa dose de biofertilizante, houve redução. A concentração de FDA apresentou um comportamento linear positivo em função do nível de biofertilizante aplicado, quando se utilizou $50 \%$ da recomendação de adubo químico. As concentrações de FDA variaram segundo a equação de $y=9,453 x+301,67\left(R^{2} 0,70\right)$, o que proporcionou concentrações de $337,25 \mathrm{~g} \mathrm{~kg}^{-1}$ e 302,85 $\mathrm{g} \mathrm{kg}^{-1}$ (base na MS) para a maior e menor dose de biofertilizante aplicada, respectivamente. Quando se associou a $100 \%$ da recomendação de adubo químico, os níveis de biofertilizante ajustaram-se ao modelo de regressão quadrático $\left(100 \%=-6,789 \mathrm{x}^{2}+39,477 \mathrm{x}+304,83, \mathrm{R}^{2}=0,86\right)$. Com isso, constatou-se que, a máxima concentração FDA, foi obtida quando 2,91 $\mathrm{L}$ de biofertilizante foram utilizados, com ponto máximo de $362,22 \mathrm{~g} \mathrm{~kg}^{-1}$. 
Tabela 1. Altura final e razão parte aérea:raiz do capim-piatã recebendo biofertilizante com doses de adubo químico, cultivado em ambiente protegido.

Table 1. Final height and aerial part ratio: root of the piatã palisade grass receiving biofertilizer with doses of chemical fertilizer, cultivated in a protected environment.

\begin{tabular}{|c|c|c|c|c|c|c|c|c|c|}
\hline \multirow[b]{2}{*}{$\begin{array}{l}\text { Adubação } \\
\text { Química }\end{array}$} & \multicolumn{5}{|c|}{ Doses de Biofertilizante (L) } & \multirow[b]{2}{*}{$\mathrm{CV}(\%)$} & \multicolumn{3}{|c|}{ Valor P Efeitos dose de biofertilizante } \\
\hline & Controle & 1 & 2 & 3 & 4 & & $\begin{array}{c}\text { Uso de } \\
\text { Biofertilizante }\end{array}$ & $\begin{array}{l}\text { Efeito } \\
\text { Linear }\end{array}$ & Efeito Quadrático \\
\hline \multicolumn{10}{|c|}{ Altura final $(\mathrm{cm})$} \\
\hline Dose zero & 79,75 & 98,50 & 100,63 & 104,00 & 108,38 & 5,83 & 0,0001 & 0,028 & 0,700 \\
\hline $50 \%$ & 98,75 & 109,75 & 107,38 & 113,25 & 114,00 & 7,20 & 0,013 & 0,453 & 0,838 \\
\hline $100 \%$ & 100,50 & 112,00 & 106,88 & 114,00 & 108,50 & 9,11 & 0,095 & 0,624 & 0,970 \\
\hline \multicolumn{10}{|c|}{ Razão parte aérea:raiz } \\
\hline Dose zero & 0,56 & 0,84 & 0,85 & 0,68 & 0,51 & 21,58 & 0,016 & 0,286 & 0,002 \\
\hline $50 \%$ & 0,73 & 0,45 & 0,49 & 0,39 & 0,32 & 24,54 & 0,002 & 0,0003 & 0,275 \\
\hline $100 \%$ & 0,85 & 0,38 & 0,43 & 0,37 & 0,41 & 22,55 & 0,0001 & 0,0001 & 0,0005 \\
\hline
\end{tabular}

Tabela 2. Proteína bruta (PB), fibra em detergente neutro (FDN) e fibra em detergente ácido (FDA) do capim-piatã recebendo biofertilizante com doses de adubo químico, cultivado em ambiente protegido.

Table 2. Crude protein (CP), neutral detergent fiber (NDF) and acid detergent fiber (ADF) of piatã palisade grass receiving biofertilizer with doses of chemical fertilizer cultivated in a protected environment.

\begin{tabular}{|c|c|c|c|c|c|c|c|c|c|}
\hline \multirow{2}{*}{$\begin{array}{l}\text { Adubação } \\
\text { Química }\end{array}$} & \multicolumn{5}{|c|}{ Doses de Biofertilizante $(\mathrm{L})$} & \multirow[b]{2}{*}{$\mathrm{CV}(\%)$} & \multicolumn{3}{|c|}{ Valor P Efeitos dose de biofertilizante } \\
\hline & Controle & 1 & 2 & 3 & 4 & & $\begin{array}{c}\text { Uso de } \\
\text { Biofertilizante }\end{array}$ & $\begin{array}{l}\text { Efeito } \\
\text { Linear }\end{array}$ & Efeito Quadrático \\
\hline \multicolumn{10}{|c|}{ Proteína bruta $\left(\mathrm{g} \mathrm{kg}^{-1}\right)$} \\
\hline Dose zero & 60,20 & 60,85 & 65,68 & 67,65 & 71,58 & 8,01 & 0,058 & 0,046 & 0,423 \\
\hline $50 \%$ & 63,50 & 68,58 & 71,50 & 69,70 & 68,98 & 8,57 & 0,421 & 0,213 & 0,158 \\
\hline $100 \%$ & 69,63 & 61,97 & 63,83 & 64,13 & 74,20 & 12,47 & 0,260 & 0,4041 & 0,057 \\
\hline \multicolumn{10}{|c|}{ Fibra em detergente neutro $\left(\mathrm{g} \mathrm{kg}^{-1}\right)$} \\
\hline Dose zero & 617,23 & 661,80 & 650,58 & 639,33 & 646,60 & 3,60 & 0,138 & 0,338 & 0,106 \\
\hline $50 \%$ & 609,45 & 614,00 & 625,20 & 656,23 & 642,40 & 6,58 & 0,489 & 0,120 & 0,830 \\
\hline $100 \%$ & 597,95 & 655,73 & 670,60 & 662,95 & 629,58 & 2,26 & 0,0001 & 0,208 & 0,0001 \\
\hline \multicolumn{10}{|c|}{ Fibra em detergente ácido $\left(\mathrm{g} \mathrm{kg}^{-1}\right)$} \\
\hline Dose zero & 330,58 & 334,93 & 332,03 & 338,25 & 333,48 & 4,61 & 0,962 & 0,713 & 0,756 \\
\hline $50 \%$ & 302,85 & 325,65 & 333,00 & 351,38 & 337,25 & 5,87 & 0,036 & 0,008 & 0,104 \\
\hline $100 \%$ & 337,35 & 359,30 & 355,18 & 360,75 & 330,33 & 5,08 & 0,092 & 0,659 & 0,012 \\
\hline
\end{tabular}

\section{DISCUSSÃO}

O aumento na massa de forragem e massa de raiz com aplicação de biofertilizante deve-se a maior disponibilidade de nutrientes as plantas. Segundo Faquin (2005), nutrientes aplicados via foliar apresentam maior absorção e, consequentemente rápida alocação para produção. Estavillo et al. (1996) verificaram alta eficiência de $\mathrm{N}$ proveniente de biofertilizante bovino em relação a doses de $\mathrm{N}$-mineral, devido a aplicação diluída e parcelada, proporcionando aumento da produtividade ao longo do tempo.

Entre os nutrientes disponíveis, o nitrogênio é o que mais impacta na produção e crescimento de parte aérea e consequentemente, das raízes, uma vez que esse elemento estimula o desenvolvimento das plantas que proporciona aumento na biomassa devido ao incremento na fixação de carbono (NABINGER, 2001). Na literatura é evidente o elevado potencial de resposta das gramíneas forrageiras ao nitrogênio. Martha Júnior et al. (2004) verificaram aumentos lineares na massa de forragem até 400 a $600 \mathrm{~kg} \mathrm{ha}^{-1} \mathrm{ano}^{-1} \mathrm{de}$ N. Utilizando biofertilizante em Dactylis glomerata, Tomasik; Vehala (1991) observaram que quanto maior a concentração de $\mathrm{N}$ no biofertilizante mais pronunciado o seu efeito na produção de massa seca, com produção semelhante a adubação com $\mathrm{N}$-fertilizante.
De acordo com França et al. (2007), o nitrogênio participa da composição de substâncias orgânicas imprescindíveis para o desenvolvimento das plantas, tais como aminoácidos, ácidos nucléicos, hormônios de crescimento e clorofila. Neste sentido, Lemaire; Chapman (1996) relataram que o nitrogênio acelera os processos de formação e desenvolvimento de folhas e perfilhos, fundamentais para o crescimento vegetal. Biserra et al. (2017) observaram aumentos significativos no desenvolvimento do capim-piatã submetido a níveis de biofertilizante associados ou não a adubação química, justificando o aumento na área foliar.

Fagundes et al. (2005) ratifica a necessidade do fornecimento de nitrogênio às plantas forrageiras, pois o suprimento de nitrogênio no solo geralmente não garante a demanda dessas plantas. Neste sentido, Macedo (2005) observou que o déficit de nitrogênio em solos com pastagens pode ser considerado com o principal fator desencadeador do processo de degradação e consequentemente, redução da quantidade e qualidade da forragem.

No entanto, outros nutrientes presentes no biofertilizante também podem promover aumentos de massa de forragem e de raiz. Silveira Junior et al. (2015) observaram que o uso de biofertilizante elevou os teores de $\mathrm{Ca}^{2+}$ trocável e $\mathrm{P}$ disponível no solo. O fósforo é importante nutriente, presente em todos os processos morfofisiológicos da planta. 
Este elemento é vital, pois constitui o ATP (Adenosinatrifosfato), a maior fonte de energia de um organismo para desempenhar suas funções biológicas, sendo importante para manter o vigor e desenvolvimento das plantas (CECATO et al., 2007). Neste sentido, Ceretta et al. (2003) verificaram uma movimentação do P para as camadas mais profundas com aplicação de maiores doses de biofertilizante, podendo justificar o aumento no desenvolvimento da massa de raízes do capim-piatã e, consequentemente, redução da razão parte aérea:raiz.

Notou-se uma resposta semelhante entre a massa de forragem e altura da planta em resposta ao uso de biofertilizante, nas condições de adubação química. Para Castagnara et al. (2011) um aumento na massa de forragem resulta do aumento da altura do dossel, em razão do aumento da massa de folhas e colmos. Niklas (1994) descreveu também que o aumento da altura determina um maior alongamento de colmos e, consequentemente, maior número de folhas na extensão desse colmo. Assim, fica evidente o efeito pronunciado do biofertilizante na melhoria da produção da parte aérea do capim-piatã.

Para concentração de proteína bruta, constatou-se efeito linear positivo do nível de biofertilizante aplicado na ausência de adubação química, fato justificado pela rápida alocação do nitrogênio na planta, proveniente do biofertilizante. Para Van Soest (1994), esse aumento na concentração de PB na planta pode ser decorrente do aumento na concentração de aminoácidos e proteínas no conteúdo celular.

No entanto, era esperados aumentos na concentração de PB nas condições de $50 \%$ da recomendação de adubação química ou quando $100 \%$ da recomendação de adubação química foram utilizados, devido a maior disponibilidade de nutrientes para plantas, o que não aconteceu. Orrico Junior et al. (2013) avaliando doses de biofertilizante (0; 100; 200 e $300 \mathrm{~kg}$ de N) no valor nutritivo do capim-piatã constataram efeito linear positivo em função das doses crescente de $\mathrm{N}$, na concentração de PB.

Os efeitos observados nas concentrações de FDN no nível de $100 \%$ da dose recomendação e FDA quando 50\% e $100 \%$ da dose recomendada de adubação química foram aplicados, podem ser atribuídos à idade da planta e possivelmente ao alongamento das folhas e colmos, conforme encontrado por Biserra et al. (2017), proporcionando maior espessura da parede celular em plantas de crescimento livre e consequentemente, promovendo elevação nessas variáveis. A maior absorção de nutrientes, principalmente nitrogênio pelas plantas, também pode ter influenciado esses resultados. Mac Adam et al. (1989) descreveram que a maior disponibilidade de nitrogênio e nutrientes para as plantas eleva a divisão celular, consequentemente, maior alongamento de folhas e colmos e diminuição da sua qualidade. Van Soest (1994) destacou a importância dos valores de FDN para verificar a qualidade das plantas forrageiras. O autor estabeleceu que os valores acima de $600 \mathrm{~g} \mathrm{~kg}^{-1}$ na MS associam-se negativamente à capacidade de consumo voluntário de forragem pelos animais e, consequentemente, reduzem o seu desempenho. Entretanto, na dose zero de adubação química, não constatou efeito das doses de biofertilizante nas concentrações de FDN e FDA, corroborando com os resultados encontrados por Soares Filho et al. (2015).

O estágio de desenvolvimento da planta apresenta ampla relação com a composição química e digestibilidade das forrageiras. Com o crescimento das forrageiras, ocorrem aumento nos teores de carboidratos estruturais e lignina, e redução no conteúdo celular, o que invariavelmente proporcionará redução na digestibilidade. Dessa forma, são alteradas as estruturas das plantas com elevação da razão caule:folha, onde as plantas mais velhas apresentam maiores proporções de colmos que de folhas, tendo, portanto, reduzido o seu conteúdo em nutrientes potencialmente digestíveis (REIS; RODRIGUES, 1993).

Pode-se observar que o capim-piatã respondeu de forma positiva a aplicação de $4 \mathrm{~L}_{\text {vaso }}{ }^{-1}$ de biofertilizante, com ponto de máxima média (melhor resposta) na massa seca de forragem e massa seca de raiz, em todas as condições de adubação química. Com isso, observou-se uma redução da razão parte aérea:raiz, ou seja, uma menor proporção da parte aérea em relação ao sistema radicular. Uma menor razão parte aérea:raiz pode significar um sistema radicular mais extenso e, possivelmente, mais eficiente na busca de nutrientes e água. Observa-se que a altura final das plantas também foi influenciada pelo uso dos níveis de biofertilizante aplicado, na dose zero ou quando $50 \%$ da recomendação de adubação química foi utilizado.

$\mathrm{O}$ aumento da altura das plantas pode ter influenciado as frações fibrosas (FDN e FDA) diminuindo a sua qualidade. Dessa forma, constatou-se que a FDN foi influenciada pelo uso do nível de biofertilizante aplicado, quando foi associado a $100 \%$ da recomendação de adubação química. Já para FDA o efeito do uso do nível de biofertilizante foi observado quando $50 \%$ da recomendação de adubação química foi utilizada.

\section{CONCLUSÕES}

A utilização de 4 litros de biofertilizante por $15 \mathrm{dm}^{-3}$ de solo, independentemente do nível de adubação química utilizada, mostrou-se eficiente no aumento da massa de forragem e de raiz do capim-piatã, na fase de implantação. A proteína bruta aumentou apenas na dose zero. No entanto, as concentrações de fibra em detergente neutro e fibra em detergente ácido foram influenciadas negativamente pelas doses de biofertilizante, provocando redução da qualidade das plantas. Dessa forma, recomenda-se a realização de pesquisa em campo para monitoramento da evolução das condições de solo e do efeito de corte nestas condições.

\section{AGRADECIMENTOS}

À Universidade Estadual de Mato Grosso do Sul (UEMS) e a Fundação de apoio ao desenvolvimento do ensino, ciência e tecnologia do estado de Mato Grosso do Sul (FUNDECT/CNPq).

\section{REFERÊNCIAS}

ARAÚJO, A. S.; SILVA, J. E. C.; SANTOS, A. C.; SILVA NETO, S. P.; DIM, V. P.; ALEXANDRINO, E. Substituição de nitrogênio por esterco bovino na produtividade de forragem e qualidade do solo. Revista Brasileira de Saúde Produção Animal, Salvador, v. 12, n. 4, p. 852-866, out/dez. 2011.

BISERRA, T. T.; PAIVA, L. M.; FERNANDES, H. J.; DUARTE, C. F. D.; FLEITAS, A. C.; SILVA, A. O. Utilização de biofertilizante e adubação química em capim-piatã (Brachiaria brizantha). Revista de Ciências 
Agrárias, Lisboa, v. 40, n. 2, p. 333-341, 2017. DOI: http://dx.doi.org/10.19084/RCA16006

CASTAGNARA, D. D.; ZOZ, T.; KRUTZMANN, A.; Uhlein, A.; MESQUITA, E. E.; NERES, M. A.; OLIVEIRA, P. S. R. Valor nutricional e características estruturais de gramíneas tropicais sob adubação nitrogenada. Archivos de Zootecnia, Córdoba, v. 60, n. 232, p. 931-942, 2011. DOI: http://dx.doi.org/10.4321/S0004-05922011000400010

CECATO, U.; CASTRO C. R. C, CANTO, M.W.; PETERNELLI, M.; ALMEIDA JÚNIOR, J.; JOBIM, C. C.; CANO, C. C. P. Perdas de forragem em capimTanzânia (Panicum maximum Jacq. cv. Tanzânia-1) manejado sob diferentes alturas sob pastejo. Revista Brasileira de Zootecnia, Viçosa, v. 30, n. 2, p. 295-301, 2001. DOI: http://dx.doi.org/10.1590/S151635982001000200001

CECATO, U.; SKROBOT, V. D.; FAKIR, G. M.; JOBIM, C. C.; BRANCO, A. F.; GALBEIRO, S.; JANEIRO, V. Características morfogênicas do capim-mombança (Panicum maximum Jacq. cv. Mombaça) adubado com fontes de fosforo sob pastejo. Revista Brasileira de Zootecnia, Viçosa, v. 36, n. 6, p. 1699-1706, 2007. DOI: https://doi.org/10.1590/S1516-35982007000800001

CERETTA, C. A.; DURIGON, R.; BASSO, C. J.; BARCELLOS, L. A. R.; VIEIRA, F. C. B. Características químicas de solo sob aplicação de esterco líquido de suínos em pastagem natural. Pesquisa Agropecuária Brasileira, Brasília, v. 38, n. 6, p. 729-735, jun. 2003. DOI: 204X2003000600009

ERTHAL, V. J. T.; FERREIRA, P. A.; PEREIRA, O. G.; MATOS, A. T. Características fisiológicas, nutricionais e rendimento de forrageiras fertigadas com água residuária de bovinocultura. Revista brasileira de engenharia agrícola e ambiental, Campina Grande, v. 14, n. 5, p. 458-466, 2010. DOI: http://dx.doi.org/10.1590/S141543662010000500002

ESTAVILLO, J. M.; GONZALES-MURUA, C.; BESGA, G.; RODRIGUES, M. Effect of cow slurry N on herbage productivity, efficiency of $\mathrm{N}$ utilization and on white clover content in a natural sward in the Basque Country Spain. Grass and Forage Science, Oxford, v. 51, n. 1, p. 1-7, 1996. DOI: https://dx.doi.org/10.1111/j.13652494.1996.tb02031.x

FAGUNDES, J. L.; FONSECA, D. M.; GOMIDE, J. A. Acúmulo de forragem em pastos de Brachiaria decumbens adubados com nitrogênio. Pesquisa Agropecuária Brasileira, Brasília, v.40, n.4, p.397-403, abr. 2005. DOI: http://dx.doi.org/10.1590/S0100204X2005000400012

FAQUIN, V. Nutrição mineral de plantas. Lavras: UFLA/FAEPE, 2005. 183 p.

FRANCA, A. F. S.; BORJAS, A. L. R.; OLIVEIRA, E. R.; SOARES, T. V.; MIYAGI, E. S.; SOUSA, V. R. Parâmetros nutricionais do capim-tanzânia sob doses crescentes de nitrogênio em diferentes idades de corte. Ciência Animal Brasileira, Goiânia, v. 8, n. 4, p. 695703, 2007.

LEAL, M. A. de A.; SILVA, V. V. Comparação entre esterco de e cama de aviário como adubação de cova e de cobertura em pimentão orgânico cultivado em estufa e a céu aberto. Horticultura Brasileira, Brasília, v. 20, n. 2, não paginado, 2002.

LEMAIRE, G.; CHAPMAN, D. F. Tissue flows in grazed plant communities. In: HODGSON, J.; ILLIUS, A. W. (Eds.). The ecology and management of grazing systems. Oxon: CAB International. 1996. p.3-36.

LIMA, J. G. A.; VIANA, T. V. A.; SOUSA, G. G.; WANDERLEY, J. A. C.; NETO, L. G. P.; AZEVEDO, B. M. Crescimento inicial do milho fertirrigado com biofertilizante. Revista Agropecuária Científica no Semiárido, Campina Grande, v. 8, n. 1, p. 39-44, 2012.

MAC ADAM, J. W.; VOLENEC, J. J.; NELSON, C. J. Effects of nitrogen on mesophyll cell division and epidermal cell elongation in tall fescue leaf blades. Plant Physiology, Washington, v. 89, p. 549-556, 1989. DOI: https://dx.doi.org/10.1104/pp.89.2.549

MACEDO, M. C. M. Pastagens no ecossistema cerrados: Evolução das pesquisas para o desenvolvimento sustentável. In: REUNIÃO ANUAL DA SOCIEDADE BRASILEIRA DE ZOOTECNIA. A produção animal e o foco no agronegócio. Goiânia: 2005. p. 56-84.

MARTHA JÚNIOR, G. B.; CORSI, M.; TRIVELIN, P. C. O.; VILELA, L.; PINTO, T. L. F.; TEIXEIRA, G. M.; MANZONI, C. S.; BARIONI, L. G. Perdas de amônia por volatilização em pastagem de capim-tanzânia adubada com ureia no verão. Revista Brasileira de Zootecnia, Viçosa, v. 33, n. 6, p. 2240-2247, 2004. DOI: http:/ /dx.doi.org/10.1590/S1516-35982004000900009

MARTHA JUNIOR, G. B.; VILELA, L.; SOUSA, D. M. G. Cerrado: uso eficiente de corretivos e fertilizantes em pastagens. Planaltina: Embrapa Cerrados, 2007. 224 p.

NABINGER, C. Manejo da desfolha. In: SIMPÓSIO SOBRE MANEJO DA PASTAGEM, Piracicaba. Anais... Piracicaba: 2001. p.192-210.

NIKLAS, K. J. Plant allometry: the scaling process. University of Chicago Press: Chicago, Illinois, 1994. 412 p.

ORRICO JÚNIOR, M. A. P.; ORRICO, A. C. A.; CENTURION, S. R.; SUNADA, N. S.; LUCAS JUNIOR, J. L. Valor nutritivo do capim Piatã adubado com diferentes doses de biofertilizante. Revista Agrarian, Dourados, v. 4, n. 21, p. 312-319, 2013.

ORRICO JÚNIOR, M. A. P.; CENTURION, S. R.; ORRICO, A. C. A.; SUNADA, N. D. Effects of biofertilizer rates on the structural, morphogenetic and productive characteristics of Piatã grass. Revista Brasileira de Zootecnia, Viçosa, v. 41, n. 6, p. 1378-1384, 2012. DOI: http://dx.doi.org/10.1590/S1516-35982012000600009

PENTEADO, S. R. Adubação orgânica - preparo de compostos e biofertilizantes. 2. ed. Campinas. 2007. $156 \mathrm{p}$.

PRIMAVESI, A. C.; PRIMAVESI, O.; CORRÊEA, L. A.; SILVA, A. G.; CANTARELLA, H. Nutrientes na fitomassa de capim-marandu em função de fontes e doses de nitrogênio. Revista Ciência e Agrotecnologia, Lavras, v. 30, n. 3, p. 562-568, 2006. DOI: http://dx.doi.org/10.1590/S1413-70542006000300024

REIS, R. A.; RODRIGUES, L. R. A. Valor nutritivo de plantas forrageiras. Jaboticabal, 1993. $26 \mathrm{p}$.

SANTOS, H. G.; JACOMINE, P. K. T.; ANJOS, L. H. C.; OLIVERIA, V. A.; LUMBRERAS, J. F.; COELHO, M. 
R.; ALMEIDA, J. A.; CUNHA, T. J. F. E OLIVEIRA, J. B. Sistema Brasileiro de Classificação de Solos. Brasília: Embrapa, 2013. 353p.

SILVA, D. J.; QUEIROZ, A. C. Análise de alimentos: métodos químicos e biológicos. 2. ed. Viçosa. 2002. $178 \mathrm{p}$.

SILVEIRA JUNIOR, O.; SANTOS, A. C.; ROCHA, J. M. L.; FERREIRA, C. L. S.; OLIVEIRA, L. B. T.; RODRIGUES, M. O. D.; RODRIGUES, M. O. D. Implantação de pastagens sob sistema monocultivo e integrado com lavoura utilizando biofertilizante de cama de aviário como adubação de cobertura. Revista Brasileira de Saúde e Produção Animal, Salvador, v. 16, n. 3, p. 499-512, 2015. DOI: http://dx.doi.org/10.1590/S1519-99402015000300003

SOARES FILHO, C. V.; HEINRICHS, R.; PERRI, S. H. V.; CORREIA, A. C. Atributos químicos no solo e produção de Cynodon dactylon cv. Tierra Verde sob doses de biofertilizante orgânico. Revista Brasileira de Saúde e Produção Animal, Salvador, v. 16, n. 1, p. 23-35, 2015. DOI: $\quad$ http://dx.doi.org/10.1590/S151999402015000100003

SOUSA, G. G.; SANTOS, E. M.; VIANA, T. V. A.; OLIVEIRA, C. M. B.; ALVINO, F. C. G.; AZEVEDO, B. M. Fertirrigação com biofertilizante bovino na cultura do feijoeiro. Revista Agropecuária Cientifica no Semiárido, Campo Grande, v. 9, n. 4, p. 76-82, 2013.

TOMASIK, J., VAHALA, Z. Cattle slurry applications to temporary grassland under different ecological condition. Vedecke Prace Vyskumneho UstavuLuk a Pasienkov-v-Bankej Bystrica, Banska Bystrica, n. 21, p. 123-132, 1991.

VAN SOEST, P. J. Nutritional ecology of the ruminant. 2. ed. Ithaca: Cornell University Press, 1994. 476 p. 